\title{
Fuzzy Modeling of the Climate Change Effect to Drought and to Wild Fires in Cyprus
}

\author{
Xanthos Papakonstantinou ${ }^{1}$, Lazaros S. Iliadis $^{1}$, Elias Pimenidis ${ }^{2}$, and Fotis Maris ${ }^{1}$ \\ ${ }^{1}$ Department of Forestry and Management of the Environment and Natural Resources, \\ Democritus University of Thrace, Pandazidou 193, Orestiada, PC 68200, Greece \\ pxanthosster@gmail.com, liliadis@fmenr.duth.gr \\ ${ }^{2}$ School of Computing IT and Engineering, University of East London UK
}

\begin{abstract}
This is an intelligent modeling of the evolution of drought and forest fires, due to climate change in Cyprus. Original annual wild fire data records (1979-2009) and data regarding meteorological parameters were used. A flexible modeling approach was proposed towards the determination of drought risk indices in all of the country. Cyprus was divided in eight polygons corresponding to eight meteorological stations. A Fuzzy Inference Rule Based System (FIRBS) was developed to produce the drought risk indices vectors for the forest regions under study. An analysis of the spatial distribution of the heat index vectors was performed. Forest fires distribution through the island was addressed. All of the results were stored by using an ArcGIS, (version 9.3) spatial data base that enables more comprehensive presentation of the most risky areas. There is a significant increase of drought in the island and this has a serious effect in the problems of forest fires and heat indices.
\end{abstract}

Keywords: Climate Change, Fuzzy Inference System, Fuzzy Drought Indices, Heat Index, Wild Fires.

\section{Introduction}

According to Olej and Hardi [1-2] sustainable development is understood as the one that ensures the fulfillment of the needs of contemporary society without jeopardizing the opportunity to meet the needs of future generations and at the same time it improves the quality of life while living within the carrying capacity of supporting ecosystems. Drought is an extreme local climate phenomenon, difficult to be defined scientifically and this is one of the reasons that make its rational management more complicated [3]. Regardless the efforts for a general definition the specialists did not manage so far to agree in one that would be globally acceptable. Some of the existing descriptions for the term refer to "Meteorological drought", "Agricultural drought" and "Hydrological drought" as a result of looking at the problem from different points of view. When the word drought is used commonly, the most often intended definition is meteorological drought. However, when the word is used by urban planners, it is more frequently in the sense of hydrological drought.

Sustainable development is and it will be one of the main objectives of the contemporary societies and thus this study concentrates not only in recording the situation in 
terms of climate change but also in producing new Artificial Intelligence tools that can provide significant assistance towards the design of effective natural disasters management policy. The drought in the island of Cyprus is slowly but continuously getting worse during the last decades due to the fact of the climate change. The Republic of Cyprus has recognized several years ago the need for the control and management of desertification with its complicated potential consequences [4-6]. The problem is influenced by natural phenomena and also by human activities. The United Nations contract on the problem became an official law of the Cyprus Republic (Act 23 (III)/1999) and it contains a special Annex for the Mediterranean countries (Annex IV) [7]. According to this Act it is obligation of each state to design a National planning towards facing the problem.

This research effort aims first in modeling establishing and testing new flexible and efficient drought risk indices (DRI) and also in investigating the effect of climate change to a major natural disaster like forest fires. A main achievement of this effort is the design and implementation of an Intelligent Fuzzy Rule based System under the MATLAB platform where the DRI model is embedded. It is a System that performs local analysis of the drought and forest fire and estimates the degree of risk. The results are stored visually in a spatial database using ARCGIS 9.3 using actual coordinates for all of the areas.

\subsection{Area of Research, Changes in the Climate Conditions}

The main characteristics of the Mediterranean Cyprus climate are hot and dry summer from mid May till mid September, the rainy but soft winter which lasts from mid November till March. There are two short transition periods spring and autumn. During the $20^{\text {th }}$ century the climate of Cyprus and especially the two main climate parameters namely rainfall and temperature have followed significant variations. More specifically in Cyprus during the last century the average rain height has dropped significantly whereas the average temperature has risen. The change rate of these meteorological features has been much higher in the second half of the $20^{\text {th }}$ century. The warmest cases of the last 100 years have been recorded during the last 20 years [7]. The problem of desertification in Cyprus is a crucial one.

\subsection{Literature Review}

Previous research efforts estimate risk mainly based on specific imposed instructions and they do not consider major aspects and features related to the problem. They use crisp boundaries in order to classify areas based on their risk. This approach is quite error prone because an area for example with $10 \mathrm{~mm}$ of rain height can be classified as "dry", whereas an area with $10.0001 \mathrm{~mm}$ as "not dry". More specifically the following stochastic research efforts have been proposed recently for modeling drought [8] and some research has been done in the direction of evaluating existing models [9]. Fuzzy modeling efforts have been done recently towards forest fire risk classification in Greece [10-14]. Finally a limited number of Soft Computing Approaches applied in drought modeling has been published in the literature [15]. 


\section{Materials and Methods}

\subsection{Data Vectors and Data Gathering}

The meteorological and cartographic data have been generously provided by the Cypriot public services. More specifically the meteorological data have been provided by the Cyprus Meteorological Service. Average monthly maximum and minimum temperatures and rainfall from eight meteorological stations located in the island for a period of thirty nine years 1979-2009 were gathered. The forest department of Cyprus provided detailed forest fire data (forest fire frequencies, cause of ignition, burned areas) and an ArcGIS shape file (.shp) with spatial and land data on the forest areas of Cyprus. Wild fire data are related to period $30^{\text {th }}$ of April 1979 to the $24^{\text {th }}$ of October 2009. Real coordinates of the center of each wild fire from 1994 till 2009 were gathered.

\subsection{A Fuzzy Inference System for the Determination of DRI}

In fuzzy algebra every piece of data belongs to a fuzzy set with a degree of membership (in the closed interval $[0,1]$ ) that is determined by a fuzzy membership function (FMF) [16-17]. Thus each case can belong to both of "Risky area" and "High Risk area" fuzzy sets with a distinct degree of membership [17]. This research aims in proposing a reliable, flexible and rational Drought Risk Index (DRI). This is achieved with the use of fuzzy sets in order to determine the partial risk indices (due to each risk parameter). These partial risk indices can be unified to a unique risk index by the employment of fuzzy relations and more specifically fuzzy conjunction Norms. Average monthly maximum temperature, average monthly minimum temperature, average monthly relative humidity, average total rainfall were considered in this research.

\subsection{Fuzzy Degree Membership Functions}

Semi-Triangular and Triangular membership functions (functions 1 and 2 respectively) were used to determine the degree of membership (DOM) of each area under study to each corresponding fuzzy risk set ([10], [12], [16]). The choice of these functions was based on the fact that they offer only one single peak point where the DOM equals 1 and thus they distinguish the areas in a more straightforward manner.

$$
\begin{aligned}
& \mu_{s}(X)=\left\{\begin{array}{l}
0 \text { if } X<a \\
(X-a) /(c-a) \text { if } X \in[a, c] \\
(b-X) /(b-c) \text { if } X \in[c, b] \\
0 \text { if } X>b
\end{array}\right. \\
& \mu_{s}(X)=\left\{\begin{array}{l}
0 \text { if } X<a \\
(X-a) /(c-a) \text { if } X \in[a, c]
\end{array}\right.
\end{aligned}
$$

Unification of Partial Risk Indices. After the determination of the partial degrees of risk due to each separate feature, the final target was the unification of all indices to a unique risk index (the DRI) for each of the eight areas under evaluation. In fact the DRI would express the degree of membership of each area to the fuzzy set "Area of 
high Drought". A special case of fuzzy relation namely the Minimum T-Norm was applied in order to perform the fuzzy conjunction. The following function 3 presents the Minimum T-Norm approach where $\mu \mathrm{A}(\mathrm{X})$ and $\mu \mathrm{B}(\mathrm{X})$ are the DOM of element $\mathrm{X}$ to the fuzzy sets A and B respectively ([12], [13], [17], [18]).

$$
\operatorname{DRI}=\operatorname{MIN}\left(\mu_{\mathrm{A}}(\mathrm{X}), \mu_{\mathrm{B}}(\mathrm{X})\right)
$$

The fuzzy conjunction performs the fuzzy "AND" operation between two fuzzy sets. This means that the minimum T-Norm determines the DOM of an element $\mathrm{x}$ to the fuzzy set A AND B. After the determination of the fuzzy sets that correspond to each parameter, the next step was the design and construction of the "Linguistic" fuzzy rules to be used for the operation of the fuzzy controller. Thus a Mamdani FIS ([1821]) was designed built and tested. The System was designed to use four risk parameters and three FMF (corresponding to "Low", "High", "Middle" linguistics) for each parameter. So according to Olej and Hajek ([1], [17]) totally $3^{4}=81$ fuzzy rules should be built, which leads to an acceptable degree of complexity.

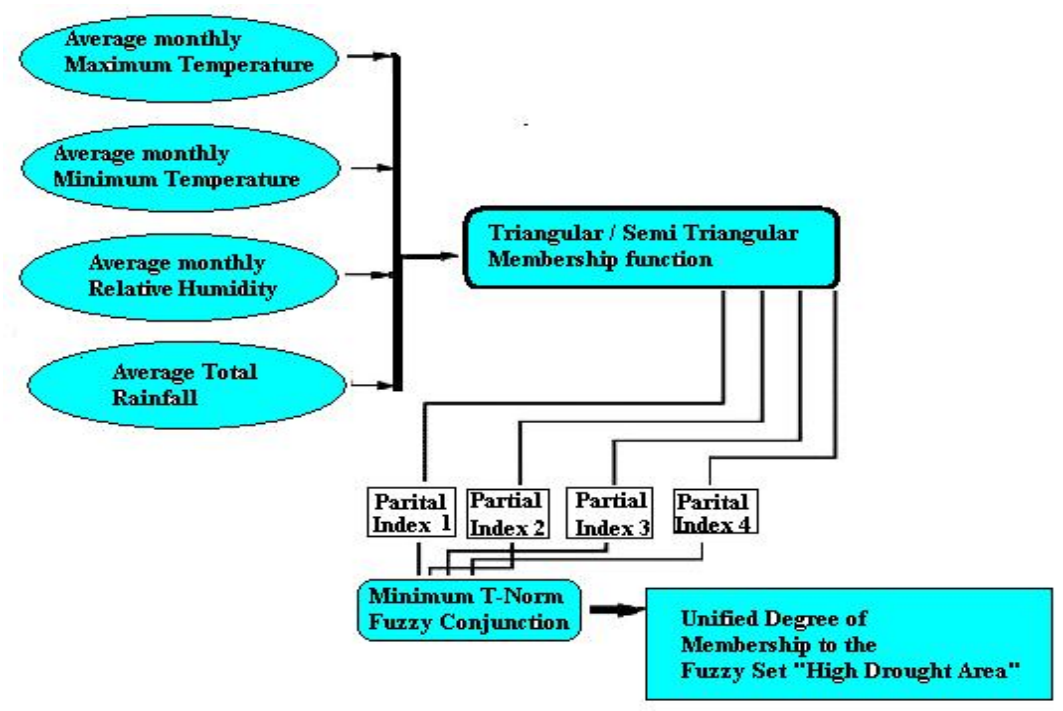

Fig. 1. Structure of the fuzzy inference system

Thus, the System was built to contain totally 81 fuzzy rules, derived from properly designed Decision Tables. It is a fact that fuzzy sets $\mu_{1}(y), \mu_{2}(y), \ldots . \mu_{p k}(y), \ldots \mu_{o}(y)$ represent the actual assignment of linguistic variables values to set $\mathrm{Y}$. Let $\left[x_{1}, x_{2}, \ldots x_{i}, \ldots x_{m}\right]$ be the input variables vector defined on the reference sets $X_{1}, X_{2}, \ldots, X_{i}, \ldots . X_{m}$ and let $y$ be an input variable defined on the reference set $Y$. In this case the FIS has $m$ input variables and one output and each set $\mathrm{X}_{\mathrm{i}}(\mathrm{i}=1,2, . ., \mathrm{m})$ can be divided in $\mathrm{p}_{\mathrm{j}}($ where $j=1,2, \ldots, n)$ fuzzy sets. 
In a Mamdani FIS the fuzzy rules can be written as follows:

IF $x_{1}$ is $A_{1}$ and $x_{2}$ is $A_{2}$ AND ....AND $x_{i}$ is $A_{p j}$ AND...AND $x_{m}$ is $A_{n}$ THEN $y$ is $B$ (where $\mathrm{i}=1,2, \ldots, \mathrm{m} \mathrm{j}=1,2, \ldots . \mathrm{n}$ ) The fuzzy rules that were actually applied had the following form:

IF (H is LOW) and ( $N$ is HIGH) and ( $\mathrm{J}$ is MIDDLE) and (C is LOW) THEN (DRI is $H I G H)$. The developed FIS outputs a matrix that contains pure numbers in the closed interval $[0,1]$ that express the degree of membership of each area to the fuzzy set "Area of high Drought".

Of course this can be considered as the matrix of the drought risk indices. Each single index is produced after the consideration of all involved meteorological parameters for each area of study and for a specific temporal value. Due to the fact that the obtained indices matrix has quite low values that are not easy to follow and to use, the risk indices were multiplied by 100 .

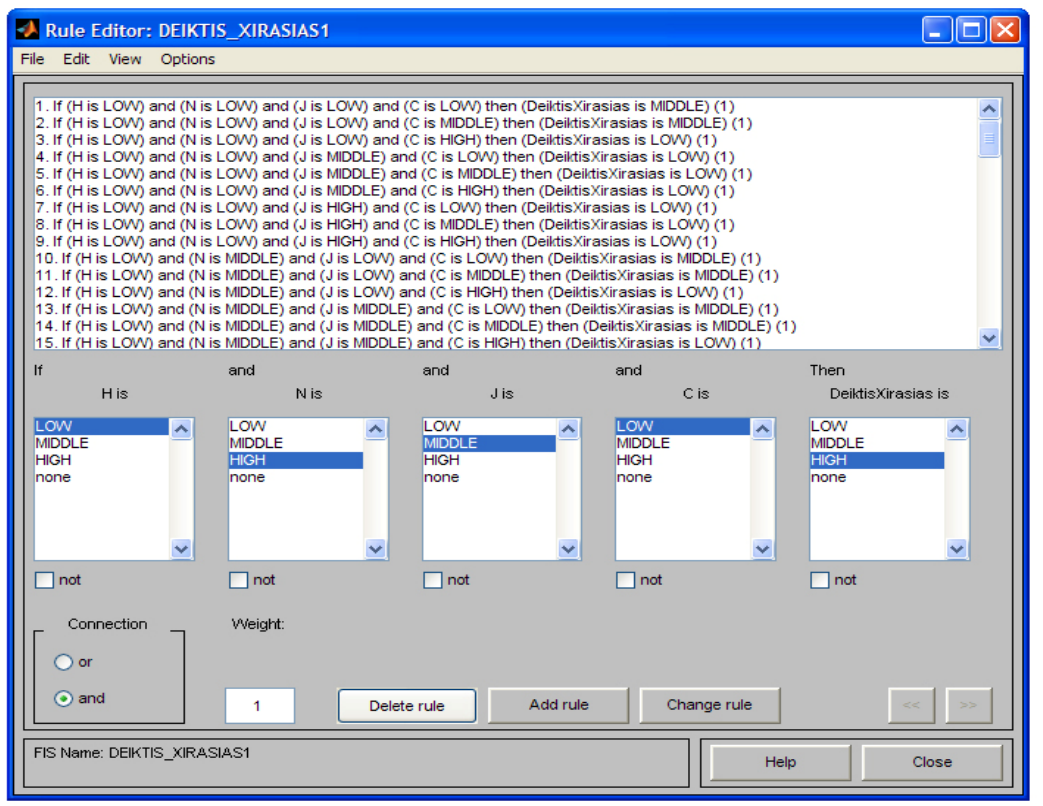

Fig. 2. Design of the fuzzy Ruleset in MATLAB

\subsection{Average Monthly Maximum Heat Index}

The determination of the average maximum Heat Index (HI) value for each area was done by using the respective average monthly maximum temperature and relative humidity values from all of the meteorological stations used. For this reason the temperatures were converted from Celsius ${ }^{\circ} \mathrm{C}$ to Fahrenheit ${ }^{\circ} \mathrm{F}$. The most widely used deterministic approach was employed for the estimation of the HI, namely the methodology proposed by the Unite States meteorological service which can be seen in the following function 4 [23]. 
$T_{H I}=16,923+1,85212 * 10^{-1} * T+5,37941 * R H-1,00254 * 10^{-1} * T^{*} R H+9,41695 *$ $10^{-3} * T^{2}+7,28898 * 10^{-3} * R H^{2}+3,45372 * 10^{-4} * T^{2} * R H-8,14971 * 10^{-4} * T^{*} R H^{2}+$ $1,02102 * 10^{-5} * T^{2} * R H^{2}-3,8646^{*} 10^{-5} * T^{3}+2,91583 * 10^{-5} * R H^{3}+1,42721 * 10^{-6} * T^{3} *$ $R H+1,97483 * 10^{-7} * T^{*} R H^{3}-2,18429 * 10^{-8} * R H^{2}+8,43296 * 10^{-10} * T^{2} * R H^{3}$ $4,81975 * 10^{-11} * T^{3} * R H^{3}$

The obtained values were manipulated by a FIS to determine the risk due HI.

\section{Using Geographic Information Systems ArcGIS}

Geographic Information Systems as dynamic tools of spatial data analysis and manipulation can be combined with fuzzy systems. They can join their forces in order to reach decisions in complex non linear and non deterministic problems such as risk modeling.

\subsection{Defining Zone Areas Using GIS}

Using ArcGIS (version 9.3) a spatial database has been developed towards the analysis and spatial representation of the most risky areas in terms of drought and according to the estimated average heat index. Also the cases were studied based on their average burned area during the last fifteen years (1994-2009). A shape ARCGIS file (.shp) of Cyrpus was employed and the free part of Cyprus (as a polygon) was divided from the occupied one, by using the cut-polygons approach. Before this division our research team performed "georeport" of the scanned map. This was done because scanned maps do not contain any piece of real coordinate data. Thus in all cases a spatial report had to be performed to the raster data in order to define the application of the data to the coordinates of the map. In other words the geo-report offered real world coordinates to each part of the map. The fact that the actual coordinates of each point of each station were known enabled the division of the limits of each meteorological station. In this way several polygons were formed in the free part of the island. This task was performed by using the ArcGIS Spatial Analyst which is an actual Extension of the System. Spatial Analyst enables the construction, analysis and mapping of raster data and the performance of an integrated raster-vector analysis [24-25]. More specifically the Path Distance Allocation methodology was employed [26].

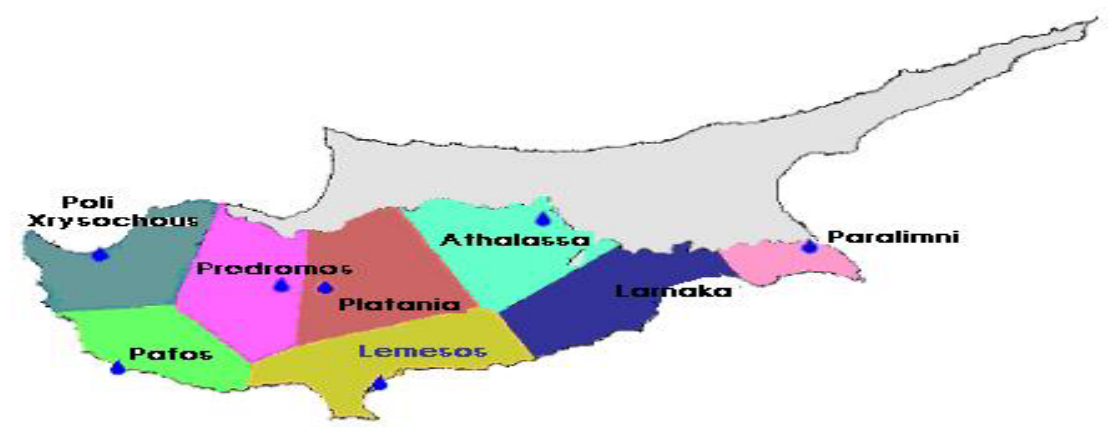

Fig. 3. Division in polygons based on the Path Distance Allocation method 
This approach recognizes for each cell the zone of the source cell which may be approached with the minimum cost. More specifically, it calculates the nearest source for each cell based on the least accumulative cost over a cost surface, while accounting for surface distance and horizontal and vertical cost factors. Finally a cut of the raster files was performed (cut polygons) and the new data were stored to correspond to the new polygons-regions.

\section{Results}

\subsection{Results Related to Drought Indices}

Figure 4 shows that the area corresponding to the meteorological station of "Athalas$s a$ " is assigned with the highest and the most stable values of the Average Maximum Drought Index (AMDI) for the period 1979-2009.

For the other areas the AMDI does not have a stable rate and it has the highest peaks during the decade 1999-2009. The highest AMDI value ever, has been recorded in the "Athalassa" meteorological station in 2008 and it is equal to 86.62706905. It should be clarified that though the obtained AMDI indices are fuzzy numbers and thus they take values in the closed interval $[0,1]$ they have been multiplied by 100 in order to be more easily understood.

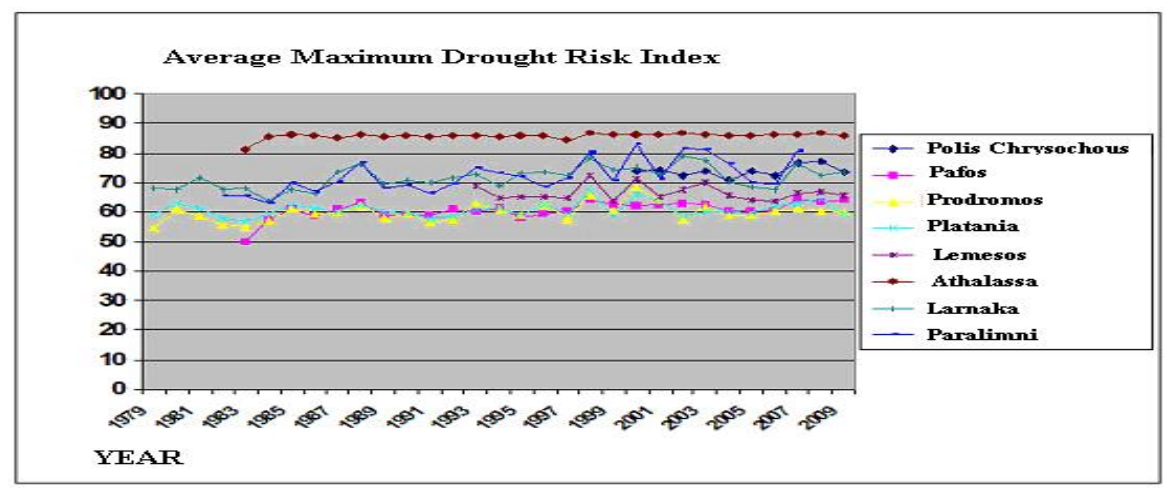

Fig. 4. Average Maximum Drought risk indices 1979-2009

The following maps (Figure 5a, 5b) are indicative graphical displays of the AMDI and of the Average Actual Values of Drought Indices (AAVDI) for the specific year 2006 and they confirm that the driest area is the one of "Athalassa".

The following graph (Figure 6), the area of "Athalassa" has also the highest AAVDI for the period 1979-2009. This area includes the central part of the country where the capital Nicosia is located and where is the residence and the working place of the majority of the population. This area has the highest $\mathrm{CO}_{2}$ emissions by vehicles and the smallest forest cover as a percentage of its surface. However the most significant result is that the AAVDI values are constantly increasing for all of the areas under study during the last decade. Even in areas such as "Prodromos" and "Platania" 
with the lowest AAVDI values and with the $2 / 3$ of the island's forested area, the problem of drought has been increasing constantly during the last decade, without any significant decrease as it used to happen during the previous two decades.

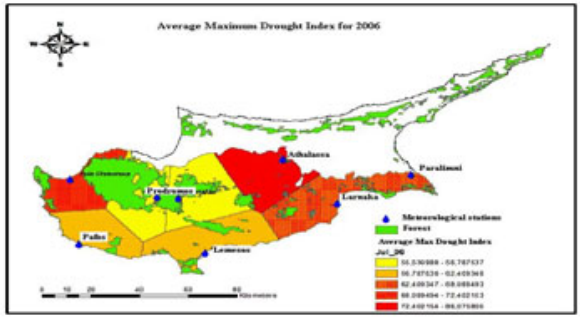

Fig. 5a. (AMDI) for 2006

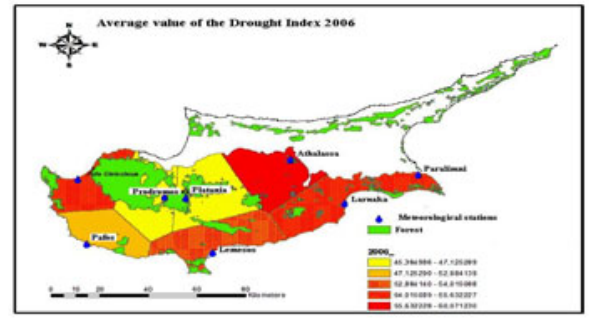

Fig. 5b. (AAVDI) for 2006

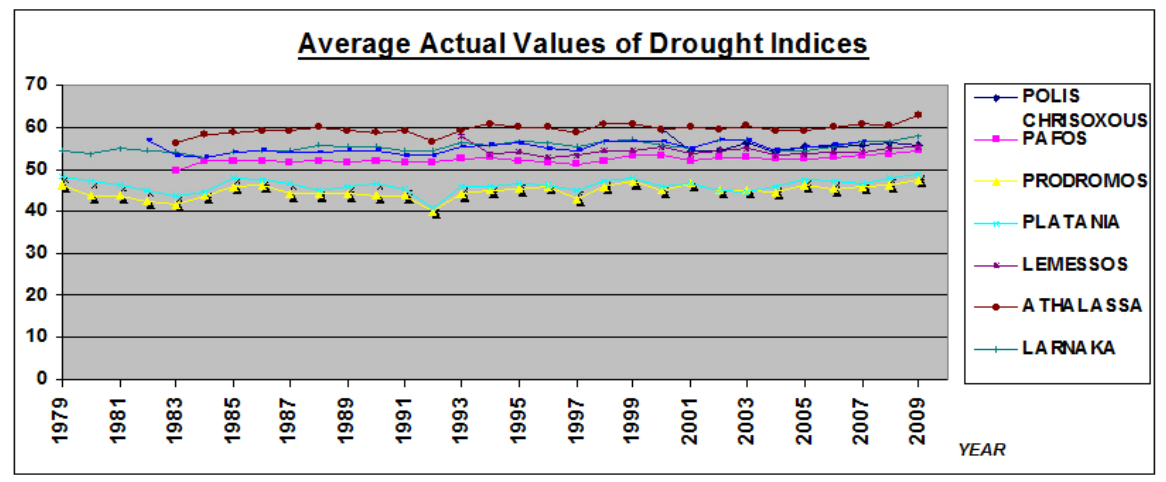

Fig. 6. AAVDI risk indices values for the period 1979-2009

From table 1 it is concluded that for the areas of "Prodromos" "Polis Chrysochous" and "Platania" which are located mainly in the center of the island the most risky month due to drought is July followed by August whereas for "Larnaka", "Athalassa", "Pafos", "Lemesos" and "Paralimni" the worst month is August followed by July. The most important result is the fact that the area of "Athalassa" which is far from the seaside has the highest average drought risk value equal to 86.6270 during August. The areas of "Prodromos" "Platania" and "Larnaka" appear 31 times to have the highest values of the average maximum drought risk index whereas "Paralimni" 26 times, "Athalassa" and "Pafos" 27 "Lemesos" 17 and "Polis Crysochous" 10. This means that though the area of "Athalassa" has the highest average values of drought risk index, the areas of "Prodromos", "Platania" and "Larnaka" have more often extreme maximum values of drought.

\subsection{Results Related to the Heat Index}

From the following graph (Figure 7) it is concluded that the area of "Athalassa" has the highest values of average maximum heat index for the period 1979-2009. This is 


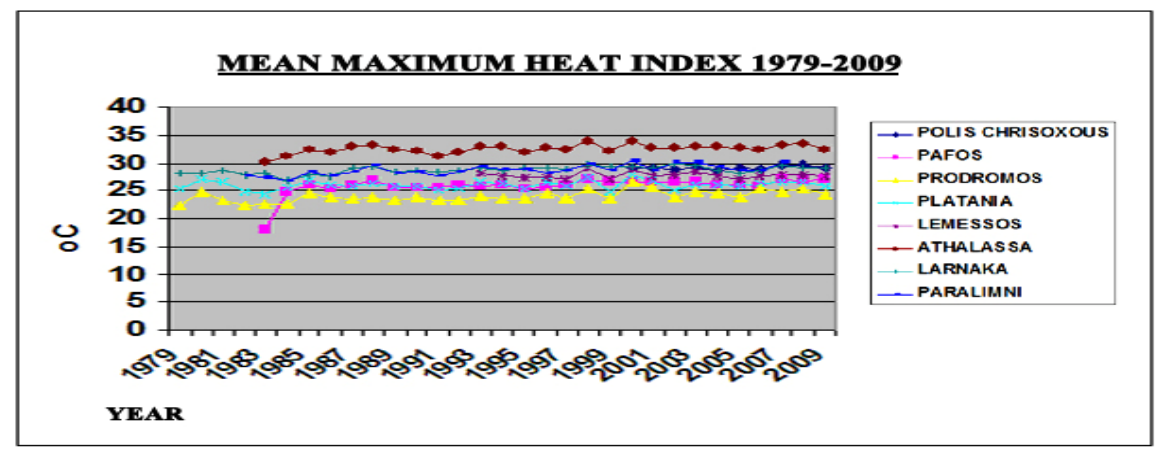

Fig. 7. Mean Maximum Heat Index 1979-2009

probably due to the fact that the area of "Athalassa" is located in the central part of the country and it contains major urban centers like the capital of Cyprus "Nicosia" where the biggest part of the country's population lives.

This area has the highest levels of air pollutants due to high traffic and the smallest ratio of forested area to the total surface. The highest value was recorded in this area during August 1998 and July 2000. In all of the other areas, the average maximum heat index risk appears to be stable for the period 1979-2009. From the following graph (Figure 8) it is concluded that the most risky area regarding the average heat index for the period 1979-2009 is "Athalassa". This is easy to be explained if we consider that this area has the highest Average Actual Values of Drought Indices and it is also mainly an urban area densely inhabited with the smallest proportion of forest cover compared to the rest of the island. The most important obtained result is that during the last five years the value of the AAVDI increases constantly even in areas with the smallest heat index values.

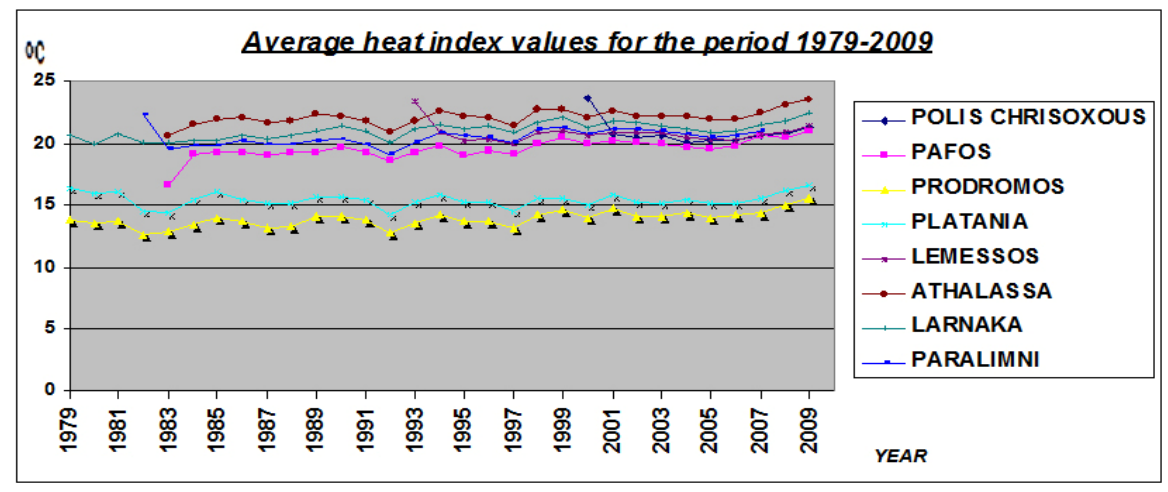

Fig. 8. Average heat index values for the period 1979-2009

It is impressive that the areas with the smallest average heat index values namely "Prodromos" and "Platania" which have a very high proportion of forest cover (they 
contain almost $66 \%$ of the whole forested area of Cyprus) appear to have a continuously increasing heat index values in the last five years.

From the following table 1 it can be seen that the most risky month regarding the heat index for the areas of "Prodromos" "Polis Chrysochous" and "Platania" is July followed by August whereas for "Larnaka" "Paralimni", "Pafos" and "Lemesos" the most risky month is August followed by July. For "Athalassa" the two months are equally risky regarding the heat index. Again the area of "Athalasa" has the highest heat index values which have been recorded in July and in August. The areas of "Prodromos" "Larnaka" and "Platania" have the highest average heat index risk values 31 times, "Paralimni" 26 times, "Athalassa" and "Pafos" 27, "Lemesos" 17 and "Polis Chrysochous" 10 times.

Table 1. Average Maximum Heat Index and AMDI X100

\begin{tabular}{|c|c|c|c|c|c|}
\hline Area & Month & $\begin{array}{l}\text { Frequency of } \\
\text { inclusion in } \\
\text { highest DRI }\end{array}$ & $\begin{array}{l}\text { Maximum } \\
\text { Average } \\
\text { DRI } \\
\end{array}$ & $\begin{array}{l}\text { Frequency of } \\
\text { inclusion in } \\
\text { highest HI } \\
\text { risk }\end{array}$ & $\begin{array}{l}\text { Average } \\
\text { Maximum } \\
\text { HI risk } \\
\end{array}$ \\
\hline \multirow{2}{*}{ Prodromos } & July & $61,29 \%$ & 682,651 & $64,52 \%$ & 26,7 \\
\hline & August & $38,71 \%$ & 657,319 & 35,48 & 25,4 \\
\hline \multirow{2}{*}{ Platania } & July & $64,52 \%$ & 658,913 & $64,52 \%$ & 27,8 \\
\hline & August & $35,48 \%$ & 673,197 & 35,48 & 27,3 \\
\hline \multirow{2}{*}{ Larnaka } & August & $61,29 \%$ & 789,141 & $64,52 \%$ & 29,8 \\
\hline & July & $38,71 \%$ & 775,406 & 35,48 & 29,6 \\
\hline \multirow{2}{*}{ Paralimni } & August & $61,29 \%$ & 810,530 & $69,23 \%$ & 30,3 \\
\hline & July & $38,71 \%$ & 829,690 & 30,72 & 30,1 \\
\hline \multirow{2}{*}{ Athalassa } & August & $66,67 \%$ & 866,270 & 48,15 & 34 \\
\hline & July & $29,63 \%$ & 855,613 & $51,85 \%$ & 34 \\
\hline Pafos & August & $77,78 \%$ & 643,002 & $77,78 \%$ & 27,1 \\
\hline Lemesos & August & $76,47 \%$ & 723,669 & $70,59 \%$ & 29 \\
\hline PolisChrisochous & July & $100 \%$ & 770,234 & $100 \%$ & 29 \\
\hline
\end{tabular}

\subsection{Results Related to Forest Fire Risk}

A few reports are available in the literature on the forest fire problem of Cyprus [27]. The problem has not been analyzed by the use of spatial decision support systems like ARCGIS or Intelligent Systems. From Figure 9 it is concluded that the majority of forest fire incidents were recorded during the last decade whereas the year 2008 was the worse so far. It should be mentioned that year 2008 had the highest average maximum drought risk index for the period 1979-2009. Obviously these two findings are related. Totally from the 1226 forest fires of the period 1979-2009 the 804 were recorded during the last decade 1999-2009.

The area of "Pafos" has the least number of forest fire breakouts (only 21 cases). "Athalassa" appears to be significantly risky with a high number of wild fires although only a small percentage of this area is forested. This finding is very important and it shows that the urbanization and land value together with the high heat index influence the problem significantly. The influence of the human factor is obvious [28]. 


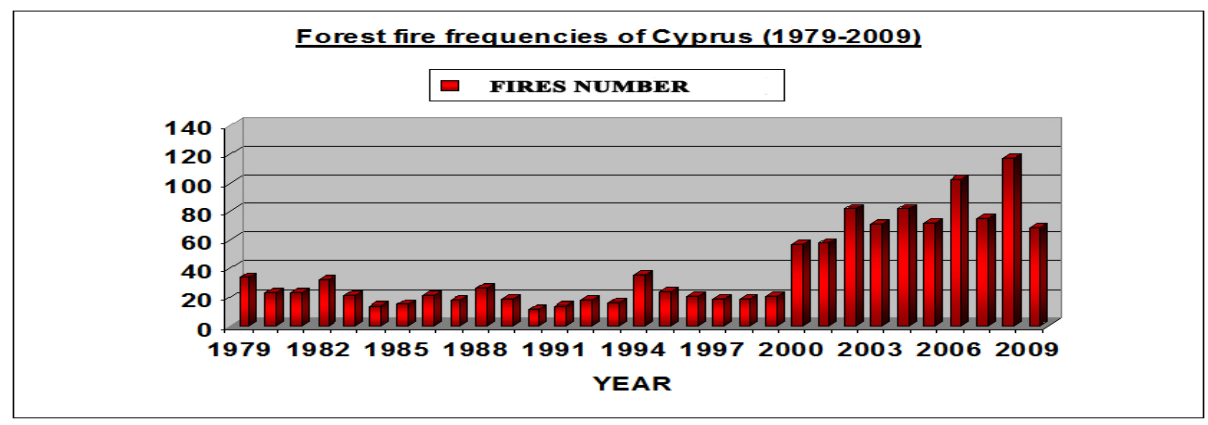

Fig. 9. Forest fire frequencies of Cyprus (1979-2009)

Totally 917 wild fires incidents appear in Figure 10, with 211 incidents in "Platania", 158 in "Prodromos" 140 in "Polis Chrysochous", 131 in "Lemesos" and 123 in "Athalassa". The area of "Pafos" has the least number of forest fire breakouts (only 21 cases). "Athalassa" appears to be significantly risky with a high number of wild fires although only a small percentage of this area is forested.

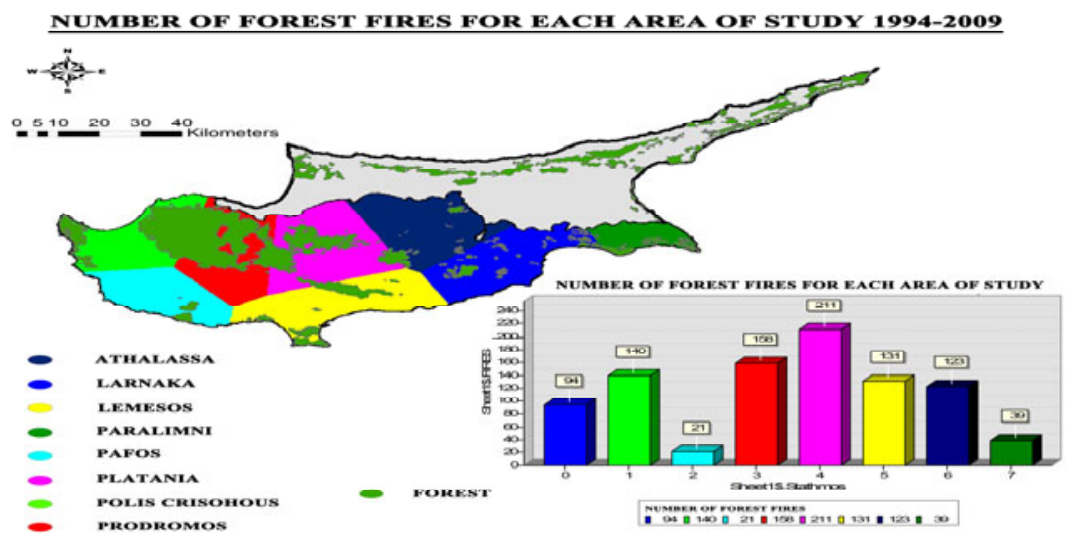

Fig. 10. Number of forest fires for each area of study

This finding is very important and it shows that the urbanization and land value together with the high heat index influence the problem significantly. The influence of the human factor is obvious [28].

\section{Discussion}

For the first time Cyprus was divided in eight polygons based on the Path Distance Allocation approach. This enabled the more comprehensive and reliable analysis of each area that demonstrated different and distinct special characteristics and properties. These areas were ranked based of the estimated DRI and on their HI values. It is 
worth mentioning that the DRI was estimated based on the equal contribution of several meteorological features something that offers a high degree of innovation to this effort. It is obvious that in Cyprus the climate conditions are changing to the worse especially during the last decade and this has an influence to the burning of forest ecosystems and to the obtained heat indices vectors that are continuously growing to higher maximum and average values A very interesting result of this research is related to the urban area of "Athalassa" where the capital Nicosia is located. Though this region has a small ratio of forest cover (forested area divided to its area) it has a very high number of wild fire incidents something that was not expected initially. This shows the influence of the drought increase and perhaps the influence of the urbanization and land value to the problem. Another crucial point is the conclusion that the DRI and the heat index are both increasing significantly during the last decade even in the areas which are located near the cost yard. This should alarm the authorities towards the design of a more effective planning. This research will continue in the future with more sophisticated Soft Computing techniques and of course with more available data.

\section{References}

1. Olej, V., Obrasalova, I., Krupka, J.: Modelling of Selected Areas of Sustainable Development by Artificial Intelligence and Soft Computing. Grada Publishing (2009)

2. Hardi, P., Barg, S.: Measuring Sustainable Development: Review of Current Practice. International Institute for Sustainable Development, Ontario, Canada (1997)

3. NAGREF: Drought A dangerous extreme climate phenomenon with special management requirements, vol. 24, pp. 10-13 (2006) (in Greek)

4. Dorflinger, G.: Assessment of Sedimentation and Erosion, Kalavasos Reservoir and Catchments, Cyprus. M.Sc. Dissertation, University of Wales, U.K (2003)

5. Kosmas, C., Kirkby, M., Geeson, N.: The Medalus project - Mediterranean desertification and land use: Manual on key indicators of desertification and mapping environmentally sensitive areas to desertification. Project ENV4 CT 95 0119, EC (1999)

6. Photiou, C.: Wastewater Treatment and Reuse-Conference on: Integrated Water Management, Policy Aspects, A.R.I. Cyprus (2003)

7. Cyprus Ministry of Agriculture, Natural Resources and Environment, National Plan for fighting the desertification, Nicosia, Cyprus (2008)

8. Ghanbarpour, M.R.: Groundwater for Sustainable Development Problems, Perspectives and Challenges. In: Bhattacharya, P. (ed.) Stochastic Modeling of Groundwater Discharge for Hydrological Drought Forecasting, ch. 14. Taylor \& Francis, Abington (2008)

9. Stockwell, D.R.B.: Critique of drought models in the Australian drought exceptional circumstances report (DECR). Energy \& Environment 21(5), 425-436 (2010)

10. Iliadis, L.: A decision support system unifying partial environmental risk indices by using fuzzy intersection operators: the case of forest fires. In: Proceedings of the HAICTA International Conference, Thessaloniki, pp. 7-16 (2004)

11. Iliadis, L.: A Decision Support System Applying an Integrated Fuzzy Model for LongTerm Forest fire Risk Estimation. Environmental Modeling and Software 20, 613-621 (2005)

12. Iliadis, L., Vangeloudh, M., Spartalis, S.: An intelligent system employing an enhanced fuzzy c-means clustering model: Application in the case of Forest Fires. Journal Computers and Electronics in Agriculture 70(2), 276-284 (2010) 
13. Iliadis, L., Skopianos, S., Tachos, S., Spartalis, S.: A Fuzzy Inference System Using Gaussian Distribution Curves for Forest Fire Risk Estimation. In: Papadopoulos, H., Andreou, A.S., Bramer, M. (eds.) AIAI 2010. IFIP AICT, vol. 339, pp. 376-386. Springer, Heidelberg (2010)

14. Iliadis, L., Zigkrika, N.: Performing Fuzzy Multi-feature Scenarios for the Determination of Forest Fire Risk. In: Proceedings of the 3rd ITAFFE 2010 International Conf., pp. 170$177(2010)$

15. Yang, D.W., Nadarajah, S.: Drought modeling and products of random variables with exponential kernel. Journal Stochastic Environmental Research and Risk Assessment 21(2), 123-129 (2006)

16. Iliadis, L.: Intelligent Information Systems and Applications in Risk Estimation. Stamouli Publishing, Thessaloniki (2007) (in Greek)

17. Kecman, V.: Learning and Soft Computing. MIT Press, London (2001)

18. Cox, E.: Fuzzy Modeling and Genetic Algorithms for Data Mining and Exploration. Elsevier Inc., USA (2005)

19. Kuncheva, L.I.: How good are Fuzzy IF-THEN Classifiers? IEEE Transactions on Systems, Man and Cybernetics 30(4), 501-509 (2000)

20. Pedrycz, W.: Fuzzy Control and Fuzzy Systems, 2nd extended edn. John Wiley \& Sons Inc., New York (1993)

21. Vascak, J., Madarasz, L.: Automatic Adaptation of Fuzzy Controllers. Acta Polytechnica Hungarica 2(2), 5-18 (2005)

22. Hajek, P., Olej, V.: Municipal Creditworthiness Modelling by means of Fuzzy Inference Systems and Neural Networks. In: Proceedings of the 4th International Conference on ISTM, TECSI-FEA Sao Paolo Brazil, pp. 586-608 (2007)

23. SCONC (State Climate Office of North Carolina) (2009), http://www.ncclimate.ncsu.edu/climate/heat_index_climatology.php

24. ArcGIS Desktop 9.3 Help 2009 Spatial Analysts (2009), http://resources.arcgis.com/content/arcgisdesktop/9.3/about

25. Hillier, A.: Working with ArcView 9.3 (2008)

26. ArcGIS Desktop 9.2 Help 2008 Path Distance Allocation, http://webhelp.esri.com/arcgiSDEsktop/9.2/index. cfm?TopicNam e=path_distance_allocation

27. IFFN Forest Fire Management in Cyprus International Forest Fire News (33), 38-43 (2005) ISSN 1029-0864

28. Cyprus Department of Forests forest fires, http://www.moa.gov. cy/forest 